\title{
Assessment of Biochemical Profile Among Patients of Gestational Diabetes Mellitus
}

\author{
Umna Rehman $^{1}$, Misbah Arshad ${ }^{1 *}$ and Amir Iqbal ${ }^{2}$
}

${ }^{1}$ University Institute of Diet and Nutritional Sciences, Faculty of Allied Health Sciences, The University of Lahore, Lahore, Pakistan

${ }^{2}$ University of Central Punjab, Lahore, Pakistan

Keywords: Gestational diabetes mellitus, Biochemical profile, HbA1c

\section{How to Cite:}

Aslam, M. ., Murtaza, F. ., Murtaza, S. ., Azhar, N. ., Abbas, N. ., Saleem, S. ., \& Manzoor, F. . (2020). Association of Dietary Practices with Mental Health Problems among Geriatrics: Dietary Practices with Mental Health Problems among Geriatrics. DIET FACTOR (Journal of Nutritional \&Amp; Food Sciences), 1(01), 11-15. https://doi.org/10.54393/df.v1i01.6

\section{Corresponding author: \\ Misbah Arshad \\ University Institute of Diet and \\ Nutritional Sciences, Faculty of \\ Allied Health Sciences, The \\ University of Lahore, Lahore, \\ Pakistan \\ fatimamisbah10@gmail.com}

\section{Article History}

Received: $19^{\text {th }}$ May 2020

Accepted: $21^{\text {st }}$ June 2020

Published: $30^{\text {th }}$ June 2020

\section{ABSTRACT}

Gestational diabetes mellitus is common but a major health problem in pregnant women. The rate of gestational diabetes mellitus has increased globally from $3 \%$ to 14\% within last 10 years. Objective: To assess the biochemical profile of women with gestational diabetes mellitus visiting public hospitals, Lahore city. Methods: A cross-sectional study was carried out at gynae department of Sir Ganga Ram Hospital, Lahore and Services Institute of Medical Sciences, Lahore within 4 months using the convenient sampling technique. The data of 100 patients were collected through pre-tested questionnaire. Data were analyzed statistically using SPSS version 21.0. Frequencies were calculated, Pearson's chi-square test was applied. Results: According to the results, $81 \%$ patients were not having insulin therapy during pregnancy and only $19 \%$ were having insulin. $73 \%$ patients had OGTT values above $200 \mathrm{mg} / \mathrm{dl}$ during pregnancy while $27 \%$ had values above $140 \mathrm{mg} / \mathrm{dl}$. An insignificant association was found between $\mathrm{HbAlc}$ test results and cereal food (paratha) consumption $(p<.72)$. Conclusions: Study concluded that more than half of female had high OGTT rate. Improper medication, irregular treatment and lack of proper medication to control diabetes during pregnancy were a major cause of high clinical test values of diabetes in pregnant women. There was no significant association between $\mathrm{HbA1c}$ test results and cereal food consumption.

\section{INTRODUCTION}

Gestational diabetes mellitus (GDM) is common but a major health problem in pregnant women. The rate of gestational diabetes mellitus has increased globally from $3 \%$ to $14 \%$ within last 10 years [1]. In Pakistan, the rate of gestational diabetes mellitus is increasing day by day [2]. Gestational diabetes mellitus is identified to be with high rates of harmful maternal and neonatal results [3]. Therefore, it is recommended to treat any form of gestational diabetes mellitus seriously [4]. It is suggested that early diagnosis and stringent control of blood glucose levels during overall pregnancy duration can reduce maternal and fetal problems [5]. Many clinicians and health care providers screen all pregnant females in their practices for gestational diabetes mellitus on routine basis [6]. A board of above 200 specialists globally has suggested some steps for gestational diabetes mellitus test and these suggestions are based on oral glucose tolerance tests [7]. The diagnosis of this disorder is often based on the outcomes of oral glucose tolerance tests [8]. Particular treatment, containing the treatment to reduce the concentration of glucose and specific obstetric management is suggested to lower the risks for mothers and their offspring during pregnancy and later in life [9]. It is confirmed that treatment of gestational diabetes mellitus has good effects on some problems of pregnancy [10]. Gestational diabetes mellitus which is not treated or not diagnosed brings major risks of perinatal illnesses and serious perinatal issues in all stages of severity of the disease [11]. High rates of 
morbidity and mortality are found in patients with uncontrolled diabetes mellitus during pregnancy [12]. The most important feature in diabetes management is self-monitoring. Monitoring the blood glucose levels four to seven times in a day is a useful contributor to improve outcomes of pregnancy as well as perinatal outcomes [13]. It is recommended in nutrition practice guideline to monitor the blood glucose levels four times per day at the beginning [14]. The rate of occurrence of progressing gestational diabetes mellitus in pregnant females is becoming greater worldwide [15]. The rate of occurrence of gestational diabetes mellitus is outlined as 2-9\% of overall pregnancies in Europe [16]. The detected rate of gestational diabetes mellitus in India was $17.8 \%$ urban females, in semi urban $13.8 \%, 9.9 \%$ in rural areas [17]. Various risk factors are associated with progression of this disease [18].

The researcher was aimed to assess the biochemical profile of women with gestational diabetes mellitus and the possible health hazards among women with pregnancy visiting public hospitals, so that awareness could be created for prevention of the factors causing this disease through health education. And the mortality and complications due to gestational diabetes mellitus in pregnant women could be reduced.

\section{METHODS}

A cross-sectional study was conducted at Public hospitals in Lahore city among 100 pregnant females suffering from gestational diabetes mellitus over the period of 4 months. A pre-tested questionnaire was used to collect data using convenient sampling technique from women with diabetes mellitus during pregnancy with informed consent. Data were analyzed using statistical package for social sciences (SPSS) version 21.0. Frequencies were calculated and Pearson's chisquare test was applied to find associations of socioeconomic status, regular checkup, mental stress, difficulty during sleep. p-value less than 0.05 was considered as significant.

\section{RESULTS}

According to the results, $81 \%$ patients were not having insulin therapy during pregnancy and only $19 \%$ were having insulin, as shown in Figure 1.

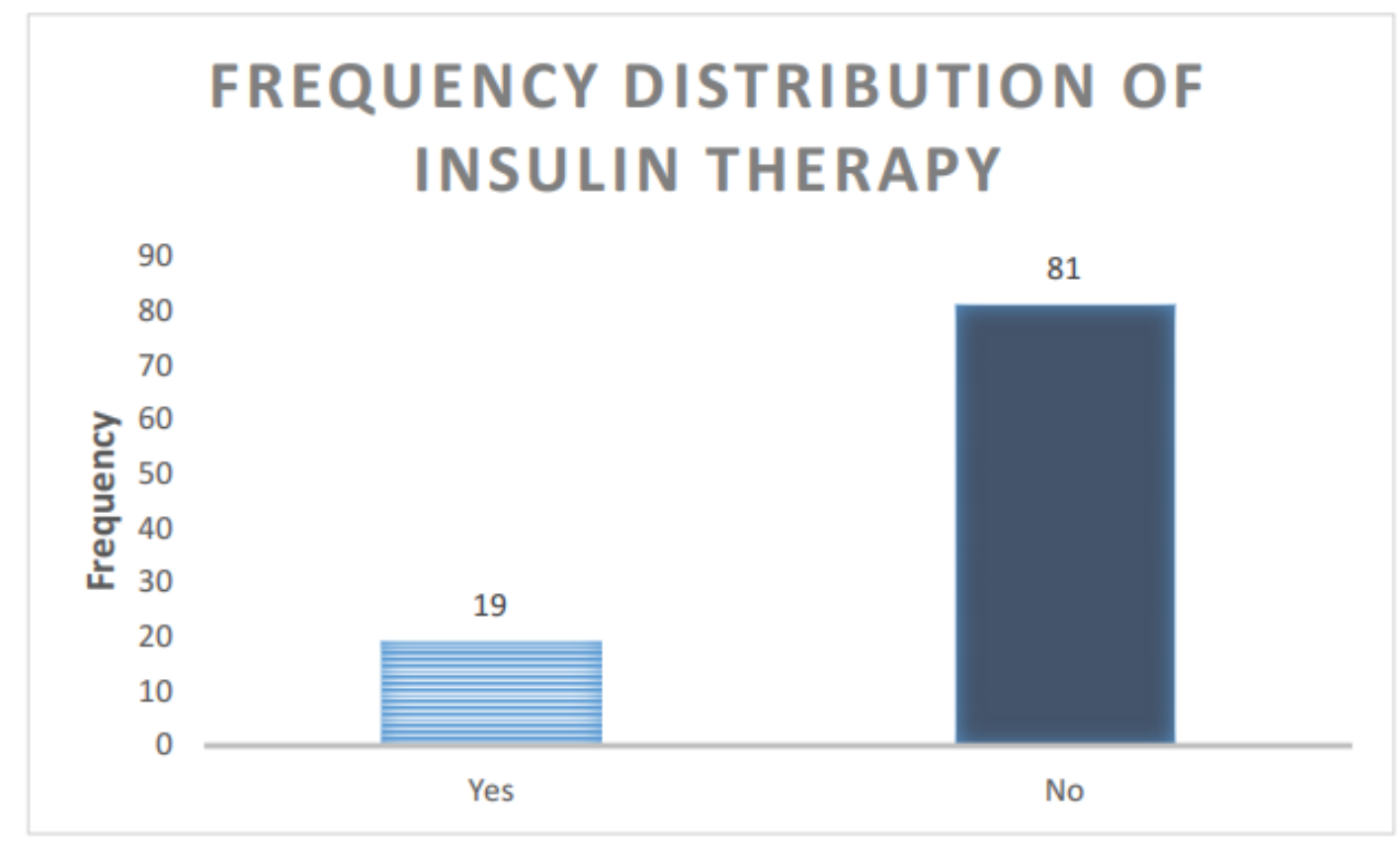

Figure 1: Frequency distribution of Insulin therapy in patients

According to the results, $73 \%$ patients had OGTT values above $200 \mathrm{mg} / \mathrm{dl}$ during pregnancy while $27 \%$ had values above $140 \mathrm{mg} / \mathrm{dl}$, as shown in Figure 2. 


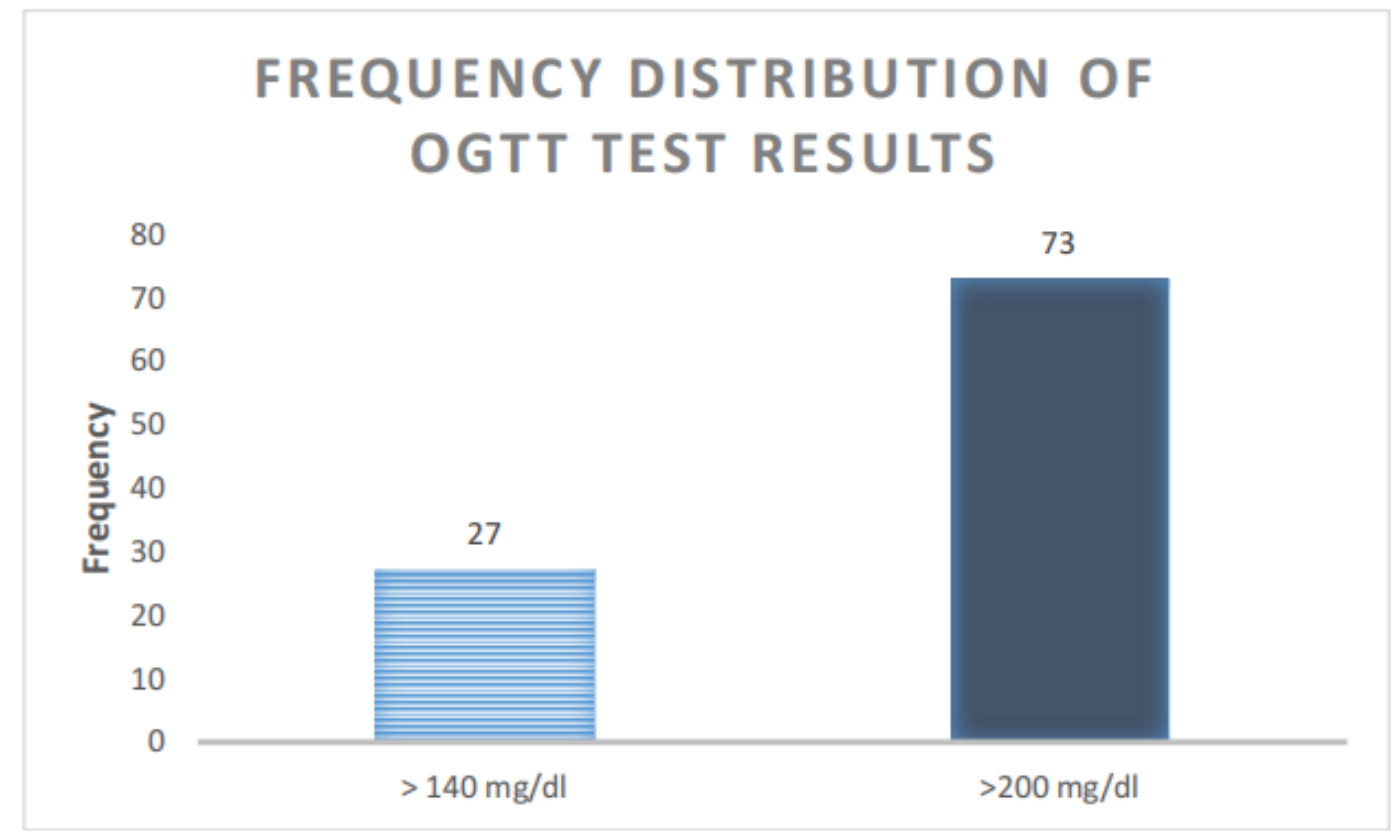

Figure 2: Frequency distribution of OGTT lab values

An insignificant result of association was found between HbA1c test results and Cereal food Paratha ( $p<.72)$, as shown in Table 1.

\begin{tabular}{|c|c|c|c|c|c|c|c|}
\hline \multirow[t]{2}{*}{ HbA1c } & \multicolumn{5}{|c|}{ Paratha consumption } & \multirow[t]{2}{*}{ Total } & \multirow[t]{3}{*}{$P$-value } \\
\hline & Daily & $\begin{array}{l}\text { 1-2 } \\
\text { times/we } \\
\text { ek }\end{array}$ & $\begin{array}{c}\text { 3-4 } \\
\text { times/ } \\
\text { week }\end{array}$ & $\begin{array}{c}\text { Once } \\
\text { a } \\
\text { week }\end{array}$ & Never & & \\
\hline$>5.7 \%$ & 13 & 8 & 22 & 6 & 1 & 50 & \\
\hline$>6.7 \%$ & 12 & 21 & 6 & 7 & 4 & 50 & \multirow[t]{2}{*}{.72} \\
\hline Total & 25 & 29 & 28 & 13 & 5 & 100 & \\
\hline
\end{tabular}

Table 1: Association between HbA1c test of patients and Cereals (Paratha)

\section{DISCUSSION}

Women suffering from gestational diabetes mellitus should take insulin to control their blood sugar levels which can affect the fetus. The results of the current study showed that $81 \%$ females were not having insulin treatment during pregnancy and only $19 \%$ were having insulin therapy. Similar results were found in a study conducted by Horvath K et al in 2010 which found the better results in pregnant women who were taking insulin but the rate of women avoiding insulin treatment was high. Study found more serious health issues in women who did not have insulin therapy throughout their pregnancy [19]. Oral glucose tolerance test is a basic clinical tool to assess the diabetes mellitus in women during their pregnancy. The alarming situation occurs if the value of oral glucose tolerance tests (OGTT) raises from $140 \mathrm{mg} / \mathrm{dl}$ and serious health issues occur if the lab values raise from $200 \mathrm{mg} / \mathrm{dl}$. The results of current study found that $73 \%$ pregnant females had their OGTT test values more than $200 \mathrm{mg} / \mathrm{dl}$ and $27 \%$ had values above $140 \mathrm{mg} / \mathrm{dl}$. Similar results were found in a study conducted by Donovan et al., in 2013 which they found the high rate of lab values of OGTT among pregnant women with diabetes mellitus [20]. In current study there was an insignificant association found between consumption of high fat containing cereals and grains with lab values of HbA1c test $(\mathrm{p}=0.72)$. 


\section{CONCLUSIONS}

Study concluded that improper medication, irregular treatment and lack of proper medication to control diabetes during pregnancy were a major cause of high clinical test values of diabetes in pregnant women.

\section{REFERENCES}

1. Buckley BS, Harreiter J, Damm P, Corcoy R, Chico A, Simmons D, Vellinga A, Dunne F. Gestational diabetes mellitus in Europe: prevalence, current screening practice and barriers to screening. A review. Diab. Med, 2012,29 (7): 844-854. doi: 10.1111/j.1464-5491.2011.03541.x

2. Seshiah V, Balaji V, Balaji MS, Paneerselvam A, Arthi T, Thamizharasi M, Datta M. Prevalence of gestational diabetes mellitus in South India (Tamil Nadu): a community based study. J. Assoc. Phy. In., 2008,56: 329-33. https://pubmed.ncbi.nlm.nih.gov/18700640/

3. Wahi P, Dogra V, Jandial K, Bhagat R, Gupta R, Gupta S, Wakhloo A, Singh J. Prevalence of gestational diabetes mellitus (GDM) and its outcomes in Jammu region. J. Assoc. Phy. In., 2011,59(4), 227-30. https://pubmed.ncbi.nlm.nih.gov/21755759/

4. Alfadhli EM. Gestational diabetes mellitus. Saudi med. J., 2015,36(4): 399. doi: 10.15537/smj.2015.4.10307

5. Bentley-Lewis R. Gestational diabetes mellitus: an opportunity of a lifetime. The Lancet, 2009, 373 (9677): 17381740. doi:https://doi.org/10.1016/S0140-6736(09)60958-2

6. Vidaeff AC, Yeomans ER, Ramin SM. Gestational Diabetes:: A Field of Controversy. Obstet. Gyne. Surv. 2003,58(11): 759-769. doi: 10.1097/01.OGX.0000093782.25261.AC

7. Coustan DR. Finding and treating gestational diabetes mellitus-does it help?. Nat. Rev. Endo. 2010,6(10): 540542. https://www.nature.com/articles/nrendo.2010.148

8. Turok DK, Ratcliffe SD, Baxley EG. Management of gestational diabetes mellitus. Ame. Fam. Phy. 2003,68(9): 1767-1772. https://pubmed.ncbi.nlm.nih.gov/14620596/

9. Ben- Haroush A, Yogev Y, Hod M. Epidemiology of gestational diabetes mellitus and its association with Type 2 diabetes. Diab. Med. 2004, 21(2): 103-113. doi: 10.1046/j.1464-5491.2003.00985.x

10. Lawrence JM, Contreras R, Chen W, Sacks DA. Trends in the prevalence of preexisting diabetes and gestational diabetes mellitus among a racially/ethnically diverse population of pregnant women, 1999-2005. Diabetes care, 2008,31(5): 899-904. doi: 10.2337/dc07-2345

11. Tobias DK, Zhang C, Van Dam RM, Bowers K, Hu FB. Physical activity before and during pregnancy and risk of gestational diabetes mellitus: a meta-analysis. Diabetes care, 2011,34(1): 223-229. doi: 10.2337/dc10-1368

12. Rajput R, Yadav Y, Nanda S, Rajput M. Prevalence of gestational diabetes mellitus \& associated risk factors at a tertiary care hospital in Haryana. Ind. J. Med. Res., 2013,137(4): 728. https://www.ijmr.org.in/article.asp?issn=09715916; year $=2013$; volume $=137$; issue $=4$; spage $=728$; epage $=733$; aulast $=$ Rajput

13. Gilmartin AB, Ural SH, Repke JT. Gestational diabetes mellitus. Rev. Obs. Gyne. 2008,1(3): 129-134. https://pubmed.ncbi.nlm.nih.gov/19015764/

14. Chu SY, Callaghan WM, Kim SY, Schmid CH, Lau J, England LJ, Dietz PM. Maternal obesity and risk of gestational diabetes mellitus. Diabetes care, 2007, 30(8): 2070-2076. doi: 10.2337/dc06-2559a

15. Shaat N, Groop L. Genetics of gestational diabetes mellitus. Curr. Med. Chem. 2007,14(5): 569-583. doi: 10.2174/092986707780059643

16. Moses RG, Barker M, Winter M, Petocz P, Brand-Miller JC. Can a low-glycemic index diet reduce the need for insulin in gestational diabetes mellitus?: A randomized trial. Diabetes care, 2009,32(6): 996-1000. doi: $10.2337 /$ dc09-0007

17. Horvath K, Koch K, Jeitler K, Matyas E, Bender R, Bastian H, Lange S, Siebenhofer A. Effects of treatment in women with gestational diabetes mellitus: systematic review and meta-analysis. BMJ, 2010,340: c1395. doi: https://doi.org/10.1136/bmj.c1395

18. Donovan L, Hartling L, Muise M, Guthrie A, Vandermeer B, Dryden DM. Screening tests for gestational diabetes: a systematic review for the US Preventive Services Task Force. Ann. Int. Med. 2013,159(2): 115-122. https://www.ncbi.nlm.nih.gov/books/NBK138424/ 